УДК 615.322:582.916.16:543.422.3

\title{
РАЗРАБОТКА И ВАЛИДАЦИЯ МЕТОДИКИ КОЛИЧЕСТВЕННОГО ОПРЕДЕЛЕНИЯ ФЛАВОНОИДОВ В ЦВЕТКАХ ФОРЗИЦИИ ПРОМЕЖУТОЧНОЙ (FORSYTHIA INTERMEDIA ZABEL.)
}

\author{
(C) В.Н. Леонова*, О.И. Попова, А.В. Красовская
}

Пятигорский медико-фрармацевтический институт - филиал ГБОУ ВПО
ВолгГМУ Минздрава России, пр. Калинина 11, Пятигорск, 357532 (Россия),
e-mail: sheryfka@mail.ru

В качестве объекта исследования использовали цветки форзиции промежуточной, которые широко применяются в народной медицине при заболеваниях печени, почек. Целью работы явилась разработка и валидация методики количественного определения суммы флавоноидов цветков форзиции промежуточной. Проведены исследования по определению оптимального экстрагента, в качестве которого был выбран $30 \%$ спирт этиловый. Ранее фармакологическими исследованиями установлено, что извлечение из цветков форзиции проявляет выраженное гепатопротекторное действие. Методом дифференциальной спектрофотометрии по реакции комплексообразования с алюминия хлоридом в исследуемом объекте установлено количественное содержание суммы флавоноидов в пересчете на рутин $(5,96 \pm 0,14 \%)$. Валидация показала, что все исследуемые валидационные параметры находятся в пределах критериев приемлемости. Предложенная авторами методика может быть включена в нормативную документацию на цветки форзиции промежуточной.

Ключевые слова: форзиция промежуточная, цветки, флавоноиды, количественное определение, дифференциальная спектрофотометрия, валидация.

\section{Введение}

Представители рода форзиция (форсайтия, Forsythia) - кустарники семейства Маслинные (Oleaceae). Род включает более 10 видов, большинство из которых происходят из Китая, Японии и Кореи, и только один вид (форзиция европейская) произрастает на Балканах. Представители рода Forsythia - необычные растения, так как сначала цветут (с марта по апрель), а потом выпускают листья и молодую поросль. Сегодня наиболее часто встречаются в садах (средней и южной полосы России) гибридные формы форзиции.

Форзиция промежуточная (Forsythia intermedia Zabel.) (средняя, гибридная) - гибрид между форзицией темно-зеленой ( $F$. viridissima) и форзицией поникшей (F. suspensa), довольно удачный морозостойкий и засухоустойчивый вид с привлекательными ярко-желтыми цветками.

Ранее нами проводились исследования биологически активных веществ (БАВ) листьев форзиции промежуточной $[1,2]$. Различными физико-химическими методами анализа (дифференциальная спектрофотометрия, высокоэффективная жидкостная хроматография) с использованием стандартных образцов в спиртовом извлечении из листьев форзиции промежуточной был установлен богатый комплекс биологически активных веществ (БАВ), в том числе наличие флавоноидов (рутина, кверцетина, нарингинина).

Леонова Виктория Нодарьевна - кандидат фармацевтических наук, преподаватель кафедры аналитической химии, e-mail: sheryfka@mail.ru Попова Ольга Ивановна - доктор фармацевтических наук, профессор кафедры фармакогнозии, профессор, e-mail: beegeeslover@mail.ru

Красовская Анастасия Викторовна - студентка, e-mail: krossik94@gmail.com
Е.Г. Доркиной с соавторами проводилось изучение гепатопротекторного действия экстракта из листьев и цветков форзиции поникшей, основными БАВ которого являются флавоноиды [3].

Для решения задачи о разработке объективных методов стандартизации необходимо проведение комплекса фитохимических и фармакологиче-

\footnotetext{
* Автор, с которым следует вести переписку.
} 
ских исследований по выявлению веществ, доминирующих не только в количественном отношении, но и определяющих фармакотерапевтический эффект растительного препарата.

Одним из актуальных направлений современной фармакогнозии является стандартизация лекарственного растительного сырья и препаратов на его основе. Это позволяет оптимизировать применение лекарственных растений для терапии различных заболеваний и, что особенно важно, осуществить разработку лекарственных форм промышленного производства на основе растительного сырья.

Поэтому целью нашей работы явилась разработка и валидация методики количественного определения суммы флавоноидов в цветках форзиции промежуточной.

\section{Экспериментальная часть}

Образцы сырья для исследования были заготовлены в апреле 2014 г. в пос. Санамер Предгорного района Ставропольского края, высушены воздушно-теневым способом. Образцы представляли собой колокольчатые цветки желтого цвета. Нами охарактеризованы внешние признаки сырья Flores Forsythia intermedia - отдельные цветки и бутоны на коротких голых цветоножках и без них. Цветки венчиковидные, иногда неправильной формы, с четырьмя слегка надрезанными ланцетовидными долями отгиба. Тычинок 8-10, со свободными шерстистыми нитями вверху и сросшихся у основания, со сросшимися пыльниками. Пестик с нижней завязью. Цвет цветков желтый. Запах слабый. Вкус - слабо-горький. Диаметр распустившихся (размоченных при анализе) цветков 10-15 мм, бутонов - 3-5 мм.

На первоначальном этапе нами были проведены исследования по выбору оптимального экстрагента для извлечения флавоноидов из исследуемого растительного сырья. В качестве экстрагента был использован этиловый спирт различных концентраций: 20, 30, 50, 70 и 90\%. Для получения пяти спиртовых извлечений брали по 1,0 г (точная навеска) сырья и проводили экстракцию этиловым спиртом, как в методике, описанной в частной фармакопейной статье на траву зверобоя $[4,5]$. В первом извлечении была проведена экстракция БАВ 20\% этиловым спиртом; во втором извлечении - 30\% этиловым спиртом; в третьем, четвертом и пятом извлечениях - 50, 70 и 90\% этиловым спиртом соответственно.

Количественное определение суммы флавоноидов в цветках форзиции проводили аналогично адаптированной методике на листья форзиции промежуточной методом дифференциальной спектрофотометрии по реакции комплексообразования с алюминия хлоридом [2]. Оптимальным экстрагентом являлся тот, который извлекал наибольшее количество суммы флавоноидов в исследуемых извлечениях. Для этого в мерную колбу вместимостью 25 мл помещали 1 мл извлечения, прибавляли 10 мл этилового спирта 95\% и 2 мл $2 \%$ спиртового раствора алюминия хлорида. Через 10 мин прибавляли 0,1 мл разведенной уксусной кислоты и доводили объем раствора в колбе до метки этиловым спиртом 95\% (раствор А).

В мерную колбу вместимостью 25 мл помещали 1 мл извлечения, прибавляли 10 мл этилового спирта 95\%. Через 10 мин прибавляли 0,1 мл разведенной уксусной кислоты и доводили до метки спиртом этиловым 95\% (раствор Б) [4, 5].

Через 30 мин измеряли оптическую плотность раствора А относительно раствора Б на спектрофотометре СФ-2000 в кюветах с толщиной слоя 10 мм при аналитической длине волны $410 \pm 2$ нм.

Параллельно измеряли оптическую плотность раствора стандартного образца (CO) рутина. Для этого около 0,05 г (точная навеска) рутина помещали в мерную колбу вместимостью 100 мл и доводили этиловым спиртом необходимой концентрации до метки. 1 мл полученного раствора помещали в мерную колбу вместимостью 25 мл и далее поступали так, как описано выше (приготовление растворов А и Б).

Расчет количественного содержания флавоноидов $(\mathrm{X}, \%)$ в пересчете на рутин в абсолютно сухом сырье проводили по формуле:

$$
X_{\%}=\frac{A_{x} \cdot a_{c m} \cdot W_{x 1} \cdot W_{x 2} \cdot V_{a c m} \cdot 100 \cdot 100}{A_{c m} \cdot a_{x} \cdot V_{a x} \cdot W_{c m 1} \cdot W_{c m 2} \cdot(100-B)}=\frac{A_{x} \cdot a_{c m} \cdot 100 \cdot 100}{A_{c m} \cdot a_{x} \cdot(100-B)}
$$

где $\mathrm{A}_{x}$ - оптическая плотность испытуемого раствора; $\mathrm{A}_{c m}$ - оптическая плотность раствора СО рутина; $a_{x}-$ навеска цветков форзиции промежуточной, г; $a_{c m}$ - масса CO рутина, г; $\mathrm{V}_{a x}$ - объем аликвоты испытуемого раствора, мл; $\mathrm{V}_{a c m}$ - объем аликвоты раствора $\mathrm{CO}$ рутина, мл; $\mathrm{W}_{x l}, \mathrm{~W}_{x 2}$ - объемы мерных колб при приготовлении испытуемого раствора, мл; $\mathrm{W}_{c m l}, \mathrm{~W}_{c m 2}$ - объемы мерных колб при приготовлении раствора СО рутина, мл; В - влажность растительного сырья, \%. 
Для проведения валидации использовали спиртовое извлечение из цветков форзиции с наибольшим содержанием флавоноидов.

Для определения специфичности методики измеряли дифференциальные спектры, полученные по реакции комплексообразования с алюминия хлоридом, спиртового извлечения из цветков форзиции промежуточной и раствора СО рутина. Определяли характер спектров и максимумы светопоглощения.

Для определения линейности методики готовили пять растворов спиртового извлечения. Для этого в пять мерных колб вместимостью 25 мл помещали 0,80; 0,90; 1,00; 1,10 и 1,20 мл извлечения соответственно, прибавляли по 10 мл этилового спирта 95\% и по 2 мл 2\% спиртового раствора алюминия хлорида. А далее поступали так, как описано выше в методике количественного определения. Эксперимент проводился в пятикратной повторности.

Прецизионность (воспроизводимость) методики определяли путем взятия шести точных навесок цветков форзиции промежуточной, приготовления шести спиртовых извлечений и определения содержания суммы флавоноидов по разработанной методике.

Для определения правильности разработанной методики из спиртового извлечения цветков форзиции промежуточной с наибольшим содержанием флавоноидов готовили три разведения $1: 0,5 ; 1: 1$ и $1: 1,5$. Для этого брали соответственно 0,$5 ; 1,0$ и 1,5 мл спиртового извлечения и проводили количественное определение суммы флавоноидов по разработанной методике. На каждом уровне концентраций рассчитывали открываемость $(\mathrm{R}, \%)[6]$.

\section{Обсуждение результатов}

Данные по выбору оптимальной концентрации экстрагента представлены в таблице 1.

Из данных таблицы 1 следует, что максимальное извлечение суммы флавоноидов достигается при использовании 30\% этилового спирта. Поэтому дальнейшие исследования проводили, используя спирт выбранной концентрации.

Специфичность. Дифференциальный спектр комплекса суммы флавоноидов с хлоридом алюминия цветков форзиции промежуточной по положению максимума светопоглощения (410 нм, рис. 1) близок к дифференциальному спектру комплекса рутина (рис. 2). Эта область спектра достаточно далека от спектров поглощения других групп фенольных соединений, содержащихся в извлечениях из растительного сырья. Использование в качестве раствора сравнения испытуемого раствора без добавления хлорида алюминия значительно повышает избирательность определения, позволяет выделить полосу поглощения комплекса суммы флавоноидов с хлоридом алюминия.

Определение линейности методики. Результаты определения линейности разработанной методики количественного определения суммы флавоноидов в $30 \%$ извлечении цветков форзиции промежуточной приведены в таблице 2 .

Для оценки линейности рассчитывали уравнение регрессии и коэффициент корреляции (рис. 3).

Значение коэффициента корреляции стремится к 1 , то есть имеется линейная зависимость методики количественного определения содержания суммы флавоноидов в 30\% извлечении цветков форзиции промежуточной методом дифференциальной спектрофотометрии.

Определение прецизионности (воспроизводимости) и правильности методики. Результаты количественного определения суммы флавоноидов в 30\% извлечении цветков форзиции промежуточной методом дифференциальной спектрофотометрии приведены в таблице 3.

Из полученных данных следует, что относительная ошибка (Е, \%) составляет 2,35\%, что свидетельствует о воспроизводимости данной методики.

Результаты определения правильности разработанной методики количественного определения содержания суммы флавоноидов в 30\% извлечении приведены в таблице 4.

Таблица 1. Выбор оптимальной концентрации экстрагента

\begin{tabular}{c|c}
\hline Концентрация этилового спирта, \% & Содержание флавоноидов, \% \\
\hline 20 & 5,40 \\
30 & 5,87 \\
50 & 5,51 \\
70 & 5,16 \\
90 & 4,83 \\
\hline
\end{tabular}




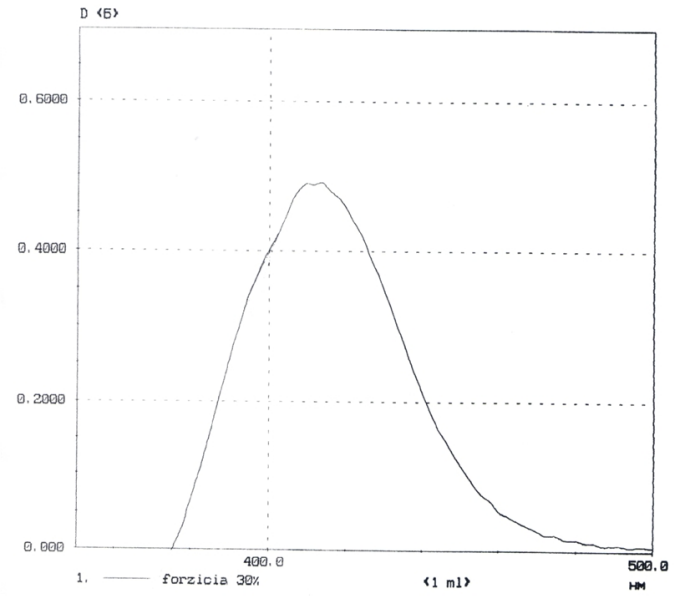

Рис. 1. Дифференциальный спектр поглощения $30 \%$ извлечения из цветков форзиции промежуточной

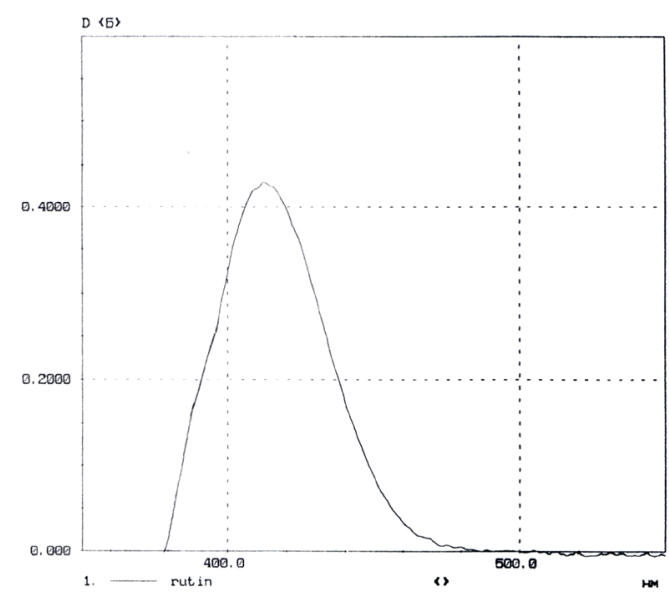

Рис. 2. Дифференциальный спектр поглощения раствора СО рутина

Таблица 2. Определение линейности разработанной методики количественного определения суммы флавоноидов в $30 \%$ извлечении цветков форзиции промежуточной $\left(a_{c m}=0,0482\right.$, $\left.\mathrm{A}_{c m}=0,429, \mathrm{~B}=6,30 \%, \mathrm{n}=5\right)$

\begin{tabular}{c|c|c}
\hline $\begin{array}{c}\text { Аликвота извлечения (по отношению } \\
\text { к декларированному объему), мл }\end{array}$ & Показания прибора $\mathrm{A}_{\boldsymbol{x} \text { средн. } \boldsymbol{y})}$ & Содержание суммы флавоноидов, \% (x) \\
\hline 0,80 & 0,424 & 4,06 \\
0,90 & 0,462 & 4,98 \\
1,00 & 0,503 & 6,02 \\
1,10 & 0,538 & 7,09 \\
1,20 & 0,580 & 8,33 \\
\hline
\end{tabular}

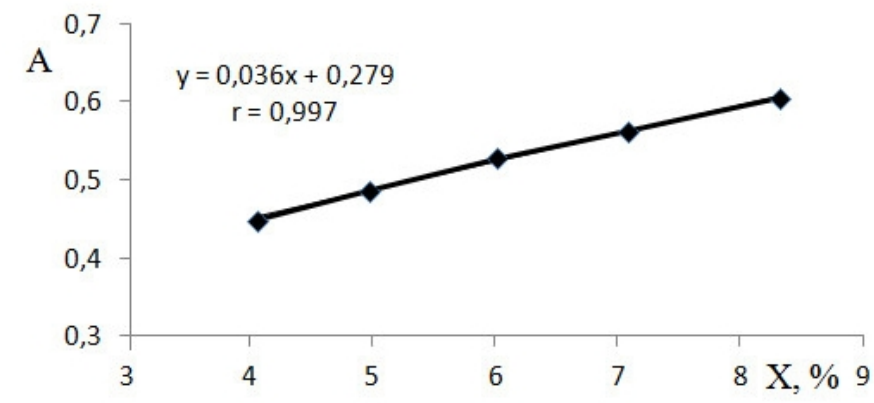

Рис. 3. Зависимость оптической плотности (А) от содержания (X, \%) суммы флавоноидов в 30\% извлечении цветков форзиции промежуточной

Таблица 3. Результаты определения критерия прецизионности методики дифференциальной спектрофотометрии при определении количественного содержания суммы флавоноидов в цветках форзиции промежуточной $\left(a_{c m}=0,0482, \mathrm{~A}_{c m}=0,429, \mathrm{~B}=6,30 \%\right)$

\begin{tabular}{c|c|c|c|c}
\hline № $\Pi / п$ & Навеска, $\Gamma$ & $\mathrm{A}_{x}$ & $\begin{array}{c}\text { Содержание суммы флаво- } \\
\text { ноидов, \% }\end{array}$ & $\begin{array}{c}\text { Метрологические характери- } \\
\text { стики }\end{array}$ \\
\hline 1 & 1,0025 & 0,490 & 5,86 & $\bar{X}=5,96 \%$ \\
2 & 1,0021 & 0,491 & 5,88 & $\mathrm{~S}=0,1332$ \\
3 & 1,0010 & 0,515 & 6,18 & $S_{\bar{X}}=0,05439$ \\
4 & 1,0050 & 0,496 & 5,92 & $\Delta \mathrm{X}=0,1398$ \\
5 & 1,0015 & 0,488 & 5,84 & $\mathrm{E}= \pm 2,35 \%$ \\
6 & 1,0013 & 0,505 & 6,05 & \\
\hline
\end{tabular}


Таблица 4. Оценка правильности методики количественного определения содержания суммы флавоноидов в цветках форзиции промежуточной

\begin{tabular}{|c|c|c|c|c|c|c|}
\hline $\begin{array}{l}\text { № } \\
\text { ח/п }\end{array}$ & Уровень & $\begin{array}{l}\text { Разведение } \\
\text { модельной } \\
\text { смеси }\end{array}$ & $\begin{array}{c}\text { Расчетное } \\
\text { содержание } \\
\text { суммы фла- } \\
\text { воноидов, \% }\end{array}$ & $\begin{array}{c}\text { Найденное со- } \\
\text { держание суммы } \\
\text { флавоноидов, \% }\end{array}$ & Открываемость, R, \% & $\begin{array}{c}\text { Метрологические ха- } \\
\text { рактеристики }\end{array}$ \\
\hline 1 & \multirow{3}{*}{ I } & $1: 0,5$ & 2,98 & 2,89 & 96,98 & \multirow{9}{*}{$\begin{array}{l}\bar{X}=96,81 \% \\
\mathrm{SD}=1,1225 \\
\mathrm{RSD}=1,16\end{array}$} \\
\hline 2 & & $1: 0,5$ & 2,98 & 2,77 & 92,95 & \\
\hline 3 & & $1: 0,5$ & 2,98 & 2,86 & 95,97 & \\
\hline 4 & \multirow{3}{*}{ II } & $1: 1$ & 5,96 & 5,88 & 98,66 & \\
\hline 5 & & $1: 1$ & 5,96 & 6,17 & 103,52 & \\
\hline 6 & & $1: 1$ & 5,96 & 5,94 & 99,66 & \\
\hline 7 & \multirow{3}{*}{ III } & $1: 1,5$ & 8,94 & 8,53 & 95,41 & \\
\hline 8 & & $1: 1,5$ & 8,94 & 8,33 & 93,18 & \\
\hline 9 & & $1: 1,5$ & 8,94 & 8,49 & 94,97 & \\
\hline
\end{tabular}

Из таблицы 4 следует, что все три уровня концентраций имеют сопоставимые результаты при относительном стандартном отклонении (RSD) 1,16\%.

Таким образом, разработанная дифференциальная спектрофотометрическая методика имеет линейный характер и является правильной и прецизионной. Поэтому она может быть включена в нормативную документацию на цветки форзиции промежуточной.

\section{Выводы}

В качестве оптимального экстрагента для получения растительного лекарственного препарата из цветков форзиции промежуточной можно использовать 30\% спирт этиловый. С помощью дифференциальной спектрофотометрии в исследуемом объекте установлено количественное содержание суммы флавоноидов в пересчете на рутин $(5,96 \pm 0,14 \%)$. Относительная ошибка определения составила $\pm 2,35 \%$. Проведена валидация разработанной методики по показателям: специфичность, линейность, прецизионность (воспроизводимость), правильность. Статистическая обработка полученных результатов показала, что все исследуемые валидационные параметры находятся в пределах критериев приемлемости.

\section{Список литературы}

1. Попова О.И., Леонова В.Н., Савенко И.А. Исследование фенольных соединений листьев форзиции промежуточной (Forsythia intermedia Zabel.) // Химия растительного сырья. 2012. №2. С. 199-201.

2. Леонова В.Н., Попова О.И., Савенко И.А. Определение флавоноидов в листьях форзиции промежуточной (Forsythia intermedia Zabel.) // Химия растительного сырья. 2013. №1. С. 175-178.

3. Доркина Е.Г., Кобин А.А., Саджая Л.А. Изучение гепатопротекторного действия сухого экстракта из форзиции поникшей и определение его эффективной терапевтической дозы // Современная медицина: тенденции развития: материалы Международной заочной научно-практической конференции. 06 мая 2013 г. Новосибирск, 2013. С. 78.

4. Государственная фармакопея СССР: в 2 т. М.: Медицина, 1990. Т. 2. 400 с.

5. Государственная фармакопея РФ: в 3 т. М.: ФЭМБ, 2015. Т. 3. С. 426-427.

6. Проект ОФС 42-0113-09. Валидация аналитических методик. М., 2009. 12 с.

Поступило в редакиию 11 июня 2016 г. 
Leonova V.N.*, Popova O.I., Krasovskaya A.V. DEVELOPMENT AND VALIDATION OF METHODS OF QUANTITATIVE DETERMINATION OF FLAVONOIDS IN THE FLOWERS OF FORSYTHIA INTERMEDIATE (FORSYTHIA INTERMEDIA ZABEL.)

Pyatigorsk Medical and Pharmaceutical Institute - a branch of Medical University VolgMU Russian Ministry of Health, pr. Kalinina, 11, Pyatigorsk,357532 (Russia),e-mail: sheryfka@mail.ru9

As object of research used the flowers of forsythia intermediate, which are widely used in folk medicine for diseases of the liver and kidney. The purpose of work was the development and validation of methods to quantify of the sum flavonoids of the flowers of forsythia intermediate. Are carried out researches by definition optimum extragent as which $30 \%$ spirit ethyl have been chosen. Previous pharmacological studies have established that an extract from the flowers of forsythia exhibits a pronounced hepatoprotective effect. The method of differential spectrophotometry by complexation reaction of aluminum chloride in investigated object installs the quantitative maintenance of the sum flavonoides in recalculation on routines $(5,96 \pm 0,14 \%)$. Validation evaluation of the proposed method carried out on such parameters as specificity, linearity, precision (repeatability), correctness. Validation showed that all the studied validation parameters are within acceptance criteria. The proposed technique by the authors can be included in the standard documentation on the flowers of forsythia intermediate.

Keywords: forsythia intermediate, leaves, flavonoids, quantitative determination, differential spectrophotometry, validation.

\section{References}

1. Popova O.I., Leonova V.N., Savenko I.A. Khimiia rastitel'nogo syr'ia, 2012, no. 2, pp. 199-201. (in Russ.).

2. Leonova V.N., Popova O.I., Savenko I.A. Khimiia rastitel'nogo syr'ia, 2013, no. 1, pp. 175-178. (in Russ.).

3. Dorkina E.G., Kobin A.A., Sadzhaia L.A. Sovremennaia meditsina: tendentsii razvitiia: materialy Mezhdunarodnoi zaochnoi nauchno-prakticheskoi konferentsii. [Modern medicine: Development Trends: Proceedings of the International correspondence scientific-practical conference]. Novosibirsk, 2013, p. 78. (in Russ.).

4. Gosudarstvennaia farmakopeia SSSR. [State Pharmacopoeia of the USSR]. Moscow, 1990, vol. 2, 400 p. (in Russ.).

5. Gosudarstvennaia farmakopeia RF. [State Pharmacopoeia of the Russian Federation]. Moscow, 2015, vol. 3, pp. 426-427. (in Russ.).

6. Proekt OFS 42-0113-09. Validatsiia analiticheskikh metodik. [Project CFC 42-0113-09. Validation of analytical methods]. Moscow, 2009, 12 p. (in Russ.).

Received June 11, 2016

Revised September 29, 2016

\footnotetext{
* Corresponding author.
} 